\title{
¿Changing Lateral Boundary Conditions for Probable Maximum Precipitation Studies: A Physically Consistent Approach
}

\author{
KARIANNe ØDemark, ${ }^{\mathrm{a}, \mathrm{b}}$ MAlte MÜller,${ }^{\mathrm{a}, \mathrm{b}}$ AND Ole EinAR TVeito ${ }^{\mathrm{a}}$ \\ ${ }^{a}$ Norwegian Meteorological Institute, Oslo, Norway \\ ${ }^{\mathrm{b}}$ Department of Geosciences, University of Oslo, Norway
}

(Manuscript received 12 March 2020, in final form 17 September 2020)

\begin{abstract}
This article presents a conceptual study toward establishing a new method for altering lateral boundary conditions in numerical model based estimates for probable maximum precipitation (PMP). We altered an extreme event in a physically and dynamically consistent way in a regional convective-scale weather prediction model (AROME-MetCoOp) by applying fields from a global ensemble climate model approach based on EC-EARTH. Ten ensemble members are downscaled with the regional model, which results in 10 different realizations of an extreme precipitation event for the west coast of Norway. We show how the position and orientation of the moisture flow is different between the individual ensemble members, which leads to relatively large changes in precipitation values for a selected catchment. For example, the modification of the moisture transport on scales of several hundred kilometers impacts the extreme precipitation amount by about $75 \%$ among the model members. Compared with historical rainfall records, precipitation changes of $62 \%$ and $71 \%$ are found for two selected catchments. Although the present study is restricted to one particular extreme event that is modified 10 times with the ensemble approach, there is a considerable spread of the moisture transport compared to the spread of the moisture transport of extreme precipitation events of the past 40 years. We conclude that the described approach is a step toward a new method to derive PMP values for a given catchment; however, a larger amount of events and larger ensembles would have to be considered to estimate PMP values.
\end{abstract}

KEYWORDS: Extreme events; Precipitation; Numerical analysis/modeling; Numerical weather prediction/forecasting; Reanalysis data

\section{Introduction}

When designing water management infrastructure, such as dams, an assessment of the theoretically maximum probable precipitation (PMP) is necessary. PMP is defined as "the greatest depth of precipitation for a given duration meteorologically possible for a given size storm area at a particular location at a particular time of year, with no allowance made for long-time climatic trends." (WMO 2009). So far, the "moisture maximization of extreme rainstorm observations" approach has been widely applied to estimate PMP. However, recent studies highlight some underlying deficiencies with the method, the results are influenced by subjective judgments of method for moisture maximization and the availability of atmospheric moisture measurements (Micovic et al. 2015). At the Norwegian Meteorological Institute (MET Norway), a standardized statistical approach based on the NERC method is used to estimate PMP (NERC 1975; Førland 1992). This approach is also vulnerable to subjective choices that strongly can affect the PMP estimates. This is in particular the case for areas where access to observations is limited.

The concept of PMP itself has recently been debated, and there are arguments that the upper limit of precipitation cannot be specified in a deterministic way (Papalexiou and Koutsoyiannis 2006; Micovic et al. 2015; Rouhani and Leconte

¿ Denotes content that is immediately available upon publication as open access.

Corresponding author: Karianne Ødemark, karianneo@met.no
2016). Ben Alaya et al. (2018) points out the difference between theoretical and operational PMP. The theoretical PMP is an unknown upper limit for precipitation, whereas operational PMP is a rational engineering solution, meaning not purely based on scientific knowledge, to provide a possible magnitude of extreme precipitation values. Hence, whether the theoretical upper limit exists or not, an operational PMP can be obtained by engineers to provide guidance for design decisions. It is important that the theoretically physical upper limit is not confused with the rational concept, as it reduces its credibility and usefulness (Klemeš 1993). When deciding on operational PMP values, the best possible knowledge should be used. The most recent World Meteorological Organization manual for estimation of PMP (WMO 2009) recommends to apply physically based atmospheric models, especially for areas where orographic precipitation is significant. A number of studies have investigated the use of numerical weather prediction models (NWPs) for PMP estimation (Ohara et al. 2011; Ishida et al. 2015a,b). Ohara et al. (2011) studied PMP for a catchment in California and applied a regional-scale highresolution physical atmospheric model. Other studies have also applied NWP-based methods to estimate PMP, where the approach is based on physical maximization of a historical extreme rainstorm. Ishida et al. (2015a) alters boundary and initial conditions to maximize precipitation over targeted catchments. Chen and Hossain (2018) pointed out that there seems to have emerged a consensus that using a physical numerical model is the way ahead for a new PMP methodology, but that there is lacking a consensus on how to physically "maximize" the historical storms within numerical models for PMP estimation. Maximizing relative humidity is often 
applied, though the question is how large effect this will give when the humidity in a historical extreme precipitation event is quite high already. Toride et al. (2019) points out that systematically saturation of all boundaries potentially introduces disturbances to the fields beyond what is realistic. In addition, a sudden change at the boundaries of the model domain can induce physical and dynamical inconsistencies.

Chen and Hossain (2018) found that there are different dominant parameters that control the storms at different locations across the continental United States. This study found that in some regions moisture availability together with vertical wind are the factors controlling the precipitation outcome, while in other regions instability controls the magnitude of the storm. The most successful approach for maximizing precipitation is by altering the parameters that will lead to the largest effect on precipitation values. A necessity is thus to know what type of atmospheric conditions lead to extreme precipitation in the area of interest.

In Norway, and in western Norway in particular, extreme precipitation is often strongly connected to atmospheric rivers (ARs) (Azad and Sorteberg 2017; Benedict et al. 2019). ARs are long, narrow patches of high vapor transport. The direction and location of the AR constrains which part of an area receives the highest amount of precipitation (Rutz et al. 2014). Ishida et al. (2015a) changed the boundary conditions in a numerical prediction model in order to place an AR to hit the selected watershed, and, in turn, increasing the amount of precipitation over the watershed.

While Ishida et al. (2015a) focused on a watershed in California, and several of the aforementioned studies are focused on numerical based methods for estimating PMP for regions in the United States, there are not yet any studies on the subject for Norway. The argument for using NWP models to estimate PMP is especially valid in areas with complex orography (WMO 2009), and the west coast of Norway has a steep topography with mountainous areas and long fjords along the coast. The largest extreme precipitation events, which are connected to the large-scale moisture flow across the Atlantic Ocean are found in western Norway (Azad and Sorteberg 2017), which is the focus area in the present study.

In the present study, we discuss an alternative method to change the boundary conditions, with emphasis on making the numerical based approach physically consistent. The aim is to make a framework with a coherent physical set up for manipulating the initial and boundary conditions. The approach utilizes synthetic events, with the advantage that we are not bound by historical events. We use a model chain, where data from a global climate model (EC-EARTH; Hazeleger et al. 2010) is applied as input to a regional weather prediction model (AROME-MetCoOp; Müller et al. 2017) in order to resolve the spatial characteristics of catchments at the Norwegian west coast. For a specific extreme precipitation event in a presentday climate simulation with EC-Earth a set of 10 perturbed ensemble members are produced and further downscaled with AROME-MetCoOp. Hence, the boundary conditions for the regional model are changed and the location of the maximum moisture flow is altered. The perturbation of the input data produces 10 ensemble members that can be considered as 10 possible realizations of a weather situation that can result in an extreme precipitation event. The realizations are starting from nearly the same atmospheric state and are equally likely. The resulting precipitation at two selected catchments are evaluated and put in context with the larger-scale differences between the ensemble members and their spread with respect to extreme events which occurred between 1981 and 2018, in order to describe what setups are conducive for the highest precipitation values.

\section{Data and methods}

The global climate model EC-Earth has been used to produce a dataset with 30 years of model data for present climate. The simulation was done with EC-Earth v2.3 (Hazeleger et al. 2010) with a horizontal resolution of $\sim 25 \mathrm{~km}$ and 91 vertical hybrid levels (T799 L91). The 30 years of simulation were constructed by six independent members spanning 5 years (2002-06). The approach for generating a dataset with ensemble members that can be considered to be independent is described in Haarsma et al. (2013). Observed greenhouse gas and aerosol concentrations were used, together with a daily satellite product for sea surface temperature.

From the 30 years of simulations, the event identified by highest daily precipitation values over a constraint area in western Norway $\left(57.1^{\circ}-63.2^{\circ} \mathrm{N}\right.$ and $\left.2.6^{\circ}-9.3^{\circ} \mathrm{N}\right)$ was selected for further study. For this event an ensemble of 10 members was established. The ensemble was constructed by stochastically perturbing the model physics tendencies (SPTT) 5 days ahead of the event, which is similar to the method used for the operational ensemble weather forecast at European Centre for Medium-Range Weather Forecasts (ECMWF; Owens and Hewson 2018). Only the lateral initial and boundary conditions are changed and the surface forcing is kept constant. Surface forcing, as SST changes, are important for extreme precipitation; however, this study is focused on changes in lateral initial and boundary conditions. Each perturbation will represent a plausible realization of a possible extreme precipitation event over the Norwegian west coast. See Schaller et al. (2020) for more details on the model setup.

Although the spatial resolution of the global climate model is considered high in comparison with state-of-the-art climate model, it is still too coarse to properly resolve the kilometerscale orographic effects important for catchment-scale precipitation estimates. To study precipitation on catchment scale a regional weather forecast model (AROME-MetCoOp; Müller et al. 2017) was used to downscale the 10 ensemble members. It is based on AROME (Applications of Research to Operations at Mesoscale; Seity et al. 2011), a nonhydrostatic atmospheric model system used operationally at the Norwegian Meteorological Institute. It is run with the standard operational domain for Scandinavia, AROMEMetCoOp, covering the entirety of Norway, as well as Sweden, Denmark, and Finland. The horizontal resolution is $2.5 \mathrm{~km}$, on a $750 \times 960$ grid, with 65 vertical layers. The simulations are initialized by the EC-Earth fields $36 \mathrm{~h}$ before the extreme event and are forced by EC-Earth fields at the lateral and upper boundaries. 
AROME-MetCoOp's ability to predict precipitation is documented in Müller et al. (2017), where forecast skills compared with the global ECMWFs Integrated Forecasting System (IFS) showed that AROME-MetCoOp clearly adds value to the forecast product for both precipitation and temperature. Since March 2014 when AROME-MetCoOp became the operational model at MET Norway it has been tuned and adapted to the specifications of our Nordic model domain, and as such it is the preferred choice of model to simulate precipitation in Norway. It permits convection, though the focus of this study is related to large-scale advective precipitation. The high horizontal resolution gives a good representation of the terrain and how it influences the spatial precipitation distribution. For the 10 members downscaled with AROME-MetCoOp, we have analyzed precipitation in two selected catchments, as well as the moisture flow at larger scales.

To compare the modeled precipitation values and in situ observations, we have retrieved observations and model data for an event with heavy precipitation (see Fig. A1 in the appendix). Daily accumulation values from three stations in the vicinity of each of the catchments are used. The event from 2013 is from the very beginning of the operational setup of AROME-MetCoOp. In this event the model underestimates precipitation compared with the observed values. For the event in 2016, the model values are comparable to the observed precipitation values. This is an example of the models ability to estimate high precipitation values, but it should be interpreted carefully. To say something conclusive about the model prediction ability, there is a need to validate the model over more than two single cases by the use of skill scores and other suitable parameters. This was done in Müller et al. (2017), and they showed that for an extreme precipitation event in 2014 and in the same area as the catchments studied here (west coast of Norway) the model performed well.

So far, the main approaches discussed in the literature to maximize precipitation with numerical models, are either to increase relative humidity, shift the boundary conditions in space, or a combination of the two (Ohara et al. 2011; Ishida et al. 2015a,b). When shifting boundary conditions the main goal is to make a historical rainstorm hit over a targeted area. To estimate the highest possible precipitation values over a catchment, the location of vapor flux is decisive.

Figure 1 shows the vertically integrated water vapor transport (IVT) corresponding to an AR simulated by EC-Earth. A detailed description of the representation of ARs in EC-Earth is given in Whan et al. (2020), where they show that the simulation of AR frequency and intensity in EC-Earth is comparable to ERA-Interim. A further evaluation of EC-Earth's ability to represent extreme IVT in the North Atlantic area has been performed in Hegdahl et al. (2020). They found that the 98th percentile of the IVT in EC-Earth is similar to ERAInterim, which confirms that results from EC-Earth can be used to identify atmospheric rivers.

Traditional PMP values are calculated for the two catchments by the current standard method at MET Norway (Førland 1992), a statistical approach based on the NERC method (NERC 1975). The precipitation values from the

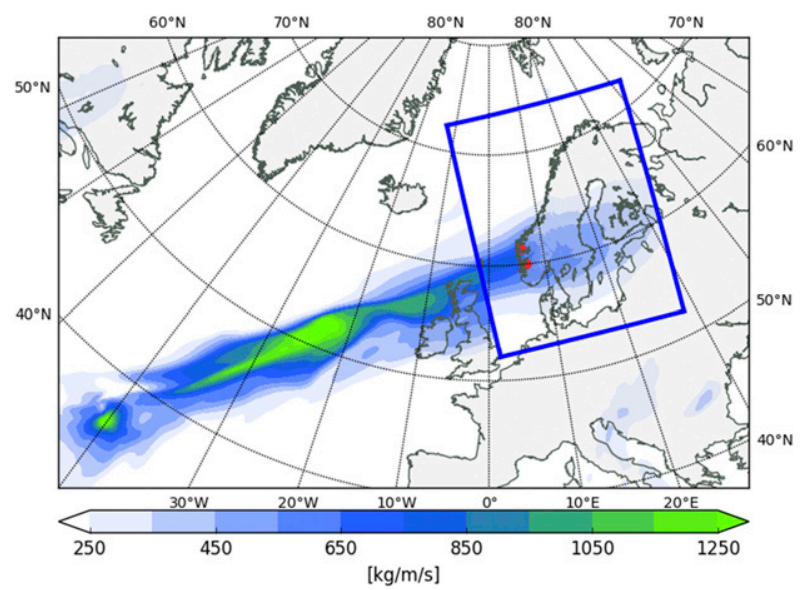

FIG. 1. Daily mean IVT simulated in EC-Earth for one of the ensemble members. Inside of the blue box, which represents the domain of AROME-MetCoOp, the displayed IVT values are from the regional model. The two red dots indicate where the two catchments used in the present study are located.

model ensemble are compared with the statistical PMP, as well as observations and return values from relevant stations in MET Norway's station network. The return values are obtained from a fit to a generalized extreme value (GEV) distribution. The GEV is fitted to peak over threshold (POT) values from the observation series, where the 99.5 th percentile threshold is used. The estimates have been calculated using the extRemes package in $\mathrm{R}$ (Gilleland and Katz 2016).

The IVT values in the ensemble are put in context with extreme events which occurred between 1980 and 2018. Observations of precipitation from six stations in and around the two catchments were used to select events where the daily precipitation amount exceeds the 99.5 percentile value. Data from 1980 through 2018 are used for each station. For the stations in Jølstra the 99.5th percentile values are 66.5, 49.1, and $58.2 \mathrm{~mm}$, while for the stations located near Opo the values are $50.0,76.9$, and $47.0 \mathrm{~mm}$. Only the dates that have precipitation values above the threshold and at the same time cooccur for all three stations in the group are used further. At the observation sites precipitation is measured from 0600 UTC one day to 0600 UTC the next day, so it is likely that most of the precipitation fell on the first of these two dates, but is registered on the last. Therefore, IVT from the day before the precipitation date is retrieved from ERA5 (Hersbach et al. 2018). ERA5 is the recently released reanalysis product from ECMWF, which comes with a finer spatial and temporal (hourly) resolution, uses a more advanced assimilation system, and includes more sources of observational data than the previous reanalysis product, ERA-Interim (Dee et al. 2011). For each extreme precipitation event selected for the two catchments the IVT pattern from ERA5 is analyzed and compared to the AROME-MetCoOp ensemble.

In the next section, the results in terms of precipitation amounts, of catchment averages and gridpoint values, of the position and direction of the IVT, and of the realism of the IVT 


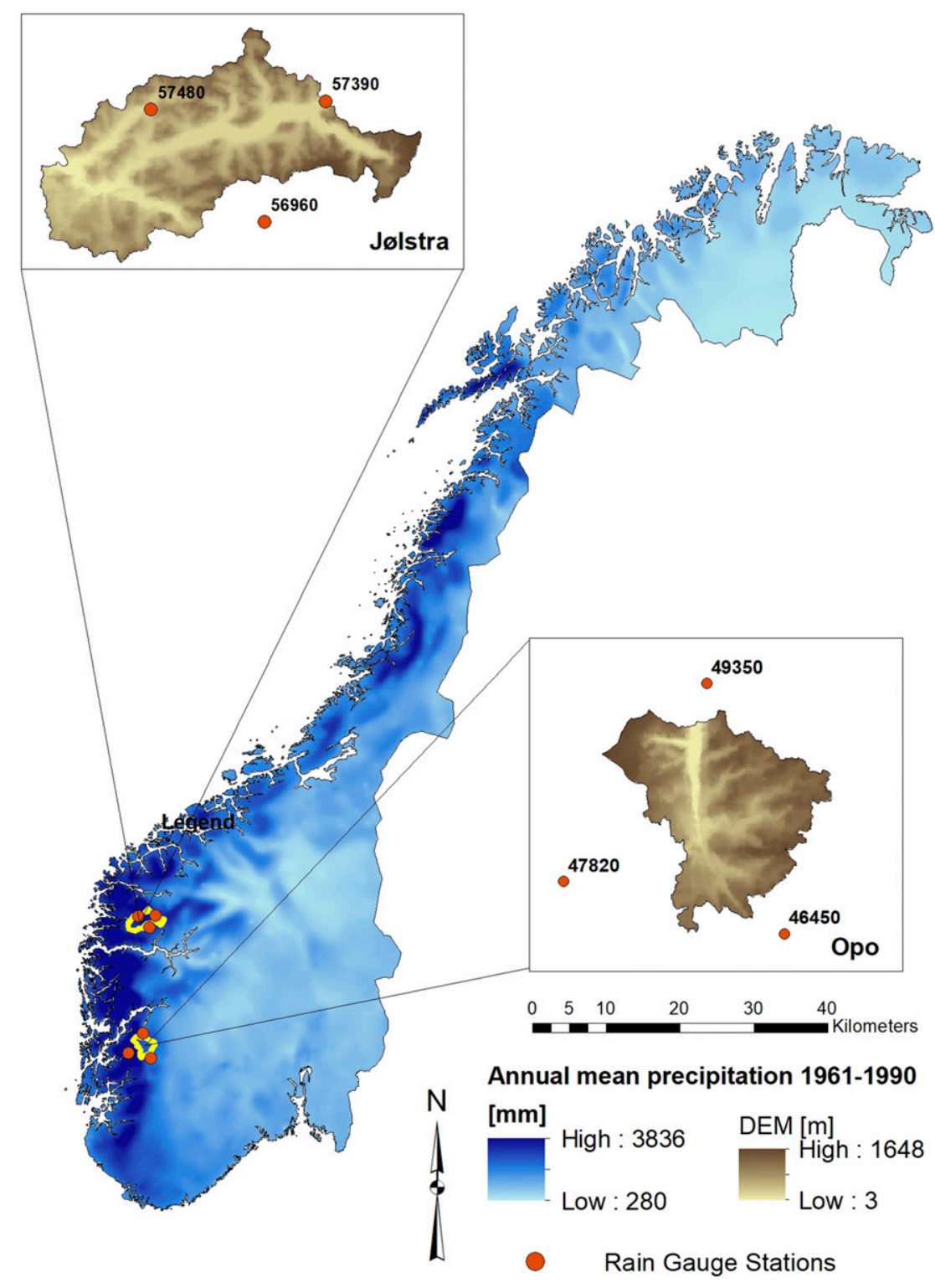

FIG. 2. Map over Norway showing annual mean precipitation and the location of the two selected catchments, Jølstra and Opo. Rain gauge stations used are indicated with orange dots. The boxes show the topography within the catchments. The annual mean precipitation is for the reference period 1961-90 (Lussana et al. 2018).

in the model ensemble are compared to historical extremes and presented in detail.

\section{Results}

Although all of the 10 ensemble members have the same synoptic structure, the perturbations result in variations of the IVT which in turn change the local-scale precipitation values. In the following, we will focus on the connection between the large-scale IVT changes close to the boundary of the regional model and the precipitation amounts in the two catchments Jølstra and Opo. These catchments are located in the western part of Norway (Fig. 2) and have catchment areas of 717 and $362 \mathrm{~km}^{2}$, respectively. The distance between the catchments are about $180 \mathrm{~km}$ and they are both located in regions with complex mountainous topography. They are therefore representative for areas that are strongly impacted by AR induced precipitation extremes.

Precipitation stations in and near the Jøstra catchment have annual mean precipitation amounts ranging from 1630 to $2666 \mathrm{~mm}$ (annual total, the 1961-90 reference period is used). The catchments elevation ranges from $0 \mathrm{~m}$ MSL at the outlet to $1648 \mathrm{~m}$ MSL as the highest elevation, and $43 \%$ of the catchment is categorized as bare mountain while $31 \%$ is categorized 

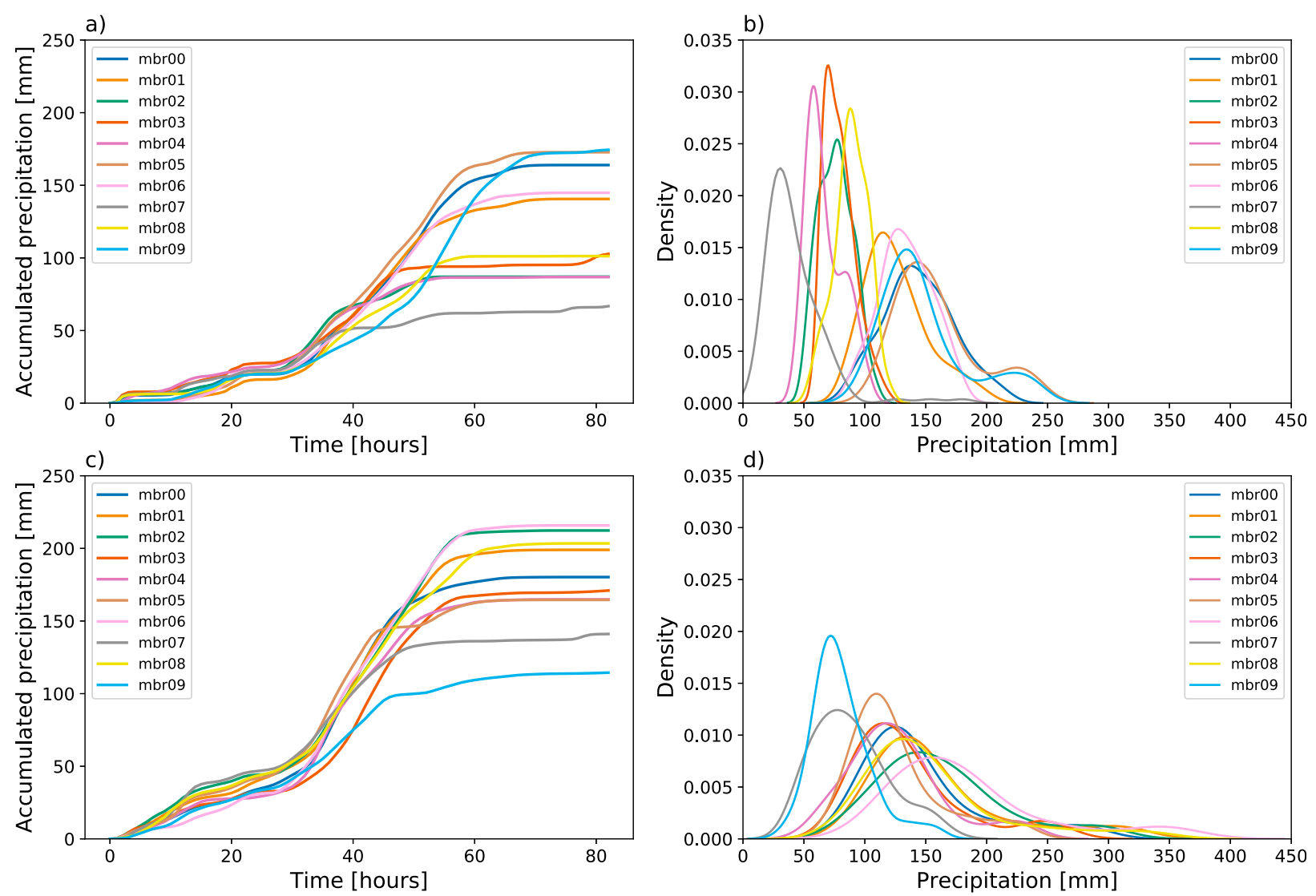

FIG. 3. Accumulated precipitation (area average) in the two catchments, (a) Jølstra and (c) Opo, and probability density distribution of the accumulation for all grid boxes within the catchments [(b) Jølstra and (d) Opo] for all ensemble members in the AROME-MetCoOp simulation. The gridbox values are accumulated over $48 \mathrm{~h}$ (during the $48 \mathrm{~h}$ with largest accumulation).

as forest. Observation stations in the vicinity of the Opo catchment have mean annual totals ranging from 1628 to $2685 \mathrm{~mm}$. Opo is also a mountain catchment with $66 \%$ categorized as bare mountain and $20 \%$ forest. Its lowest point is $88 \mathrm{~m} \mathrm{MSL}$, and the highest is $1635 \mathrm{~m}$ MSL. See the inset figures in Fig. 2 for an elevation model of the two catchments and the mean annual precipitation in the map of Norway in the same figure.

Analyzing the evolution of accumulated precipitation (catchment average) for Jølstra and Opo in the AROME-MetCoOp simulations reveals that some of the ensemble members have significant different accumulated precipitation values (Figs. 3a,c). In Jølstra (Fig. 3a), most of the members have highest precipitation accumulation during the second and third day of the model run (between hours 30 and 60), after which the accumulation stops, except member 9 which has a different timing than the others. The members with highest precipitation accumulation (members 5 and 9) have about $75 \mathrm{~mm}$ higher precipitation than in the two lowest (members 2 and 4), while in Opo (Fig. 3c) the members with highest and lowest precipitation values have a difference of about $100 \mathrm{~mm}$.

Area averages can conceal the large variations of precipitation values over an area and one single gridpoint value is not likely to represent the catchment wide rainfall. In Figs. 3b and 3d, 48-h accumulated precipitation values in all the grid boxes within the catchments are shown. Accumulated values of 247 and $241 \mathrm{~mm}$ can be found in Jølstra for two of the members and values above $300 \mathrm{~mm}$ for several of the members in Opo, with $364 \mathrm{~mm}$ as the highest value. For 24-h accumulation, the maximum amounts are $183 \mathrm{~mm}$ for Jølstra and $203 \mathrm{~mm}$ for Opo (not shown).

Daily accumulation in historical rainfall events for stations in the vicinity of the catchments show that the 24-h accumulation in the ensemble members are producing precipitation well above what is recorded (Fig. 4). The maximum model value for Jølstra is $62 \%$ higher than the highest recorded rainfall, for Opo the model maximum is $71 \%$ higher than the highest recorded rainfall.

Compared to PMP values calculated with MET Norway's standardized statistical method, accumulated values from the model are somewhat lower. In Table 1 PMP estimates are given for 24, 48, and $72 \mathrm{~h}$ for Jølstra and Opo. For accumulation over $48 \mathrm{~h}$ (Figs. 3b,d), the highest values are around $250 \mathrm{~mm}$ in the model (for Jølstra), while the original PMP value is $470 \mathrm{~mm}$. For $24 \mathrm{~h}$ the model has an accumulation of $183 \mathrm{~mm}$, while the PMP is $360 \mathrm{~mm}$. For both durations the model results are about $50 \%$ of the statistically derived PMP. For Opo the model values are closer to the statistical PMP, here the 24-h 
a)

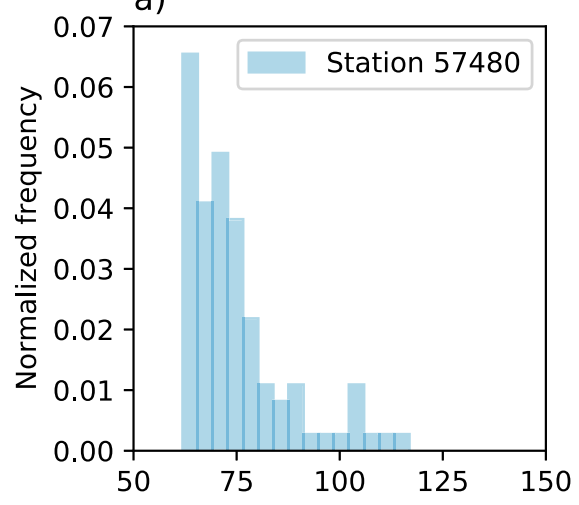

b)

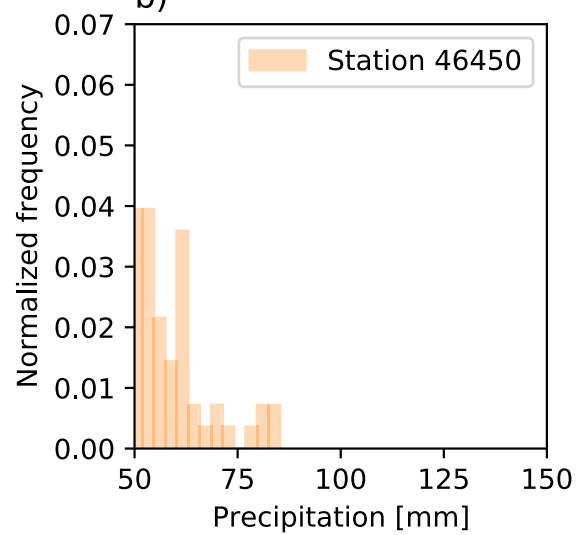

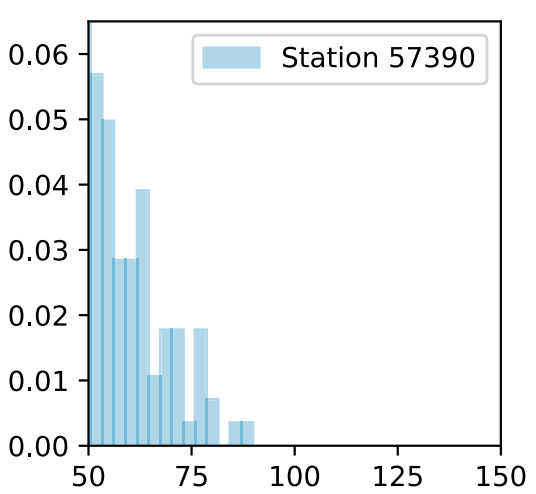
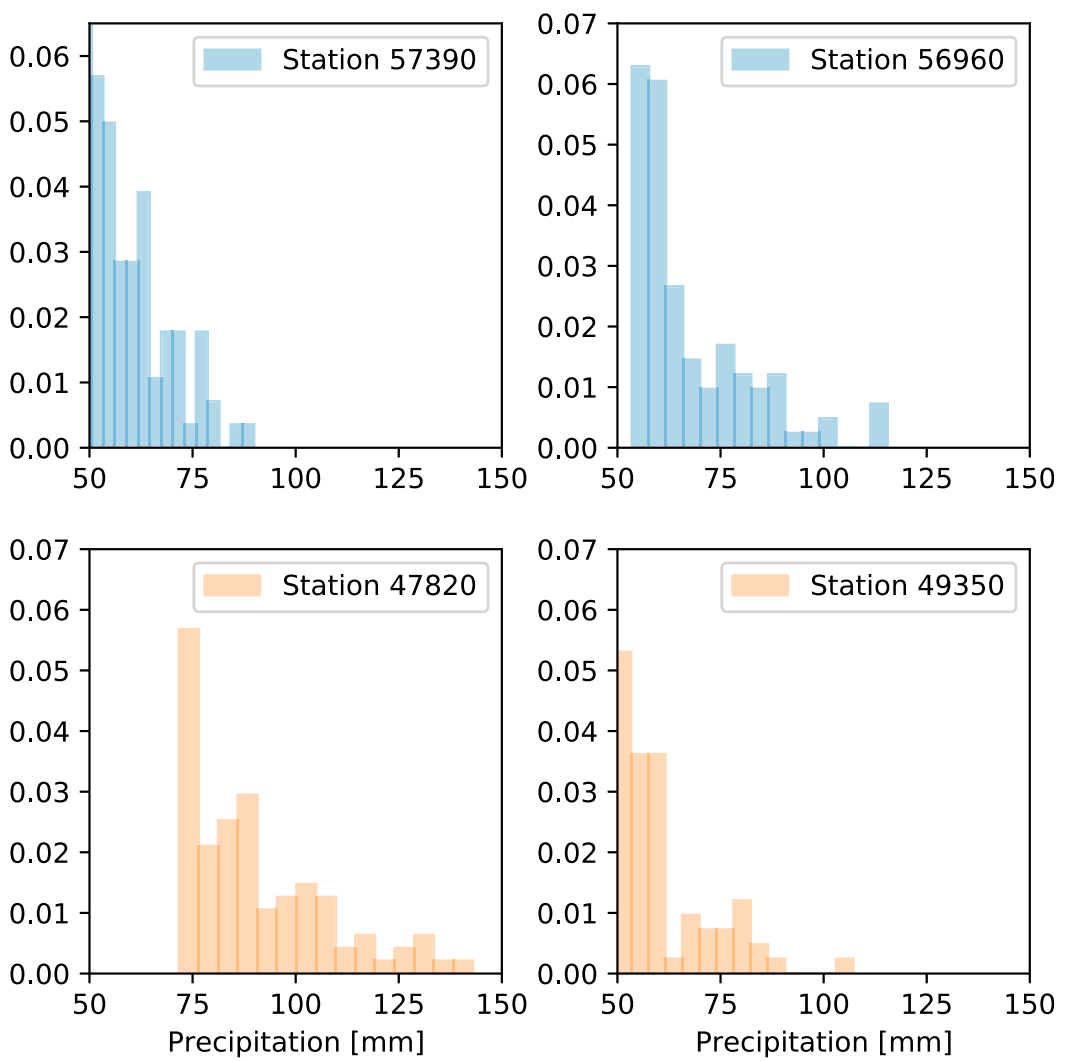

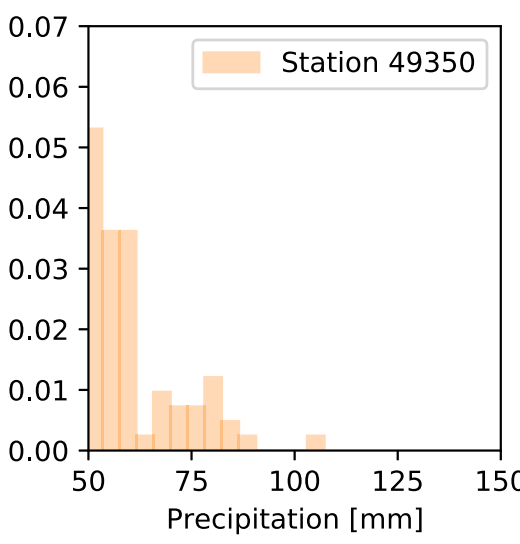

FIG. 4. Historical rainfall records for the 100 highest 24-h events selected from the station's entire time series, for observation stations near the (a) Jølstra and (b) Opo catchments.

model value is about $60 \%$ of the original PMP, and the $48-\mathrm{h}$ value is $78 \%$. The return values obtained from a fit to a generalized extreme value (GEV) distribution for the same six stations as in Fig. 4 are shown in Fig. 5. For 24-h precipitation the model results have return periods laying between a couple of thousand years and on the order of $10^{4}$ years. For the longest return periods in the figure the values must be read with caution, as the confidence intervals are very large, but still interesting as a way to put the model results and original PMP in context.

To understand what is causing the differences in precipitation amounts between the AROME-MetCoOp members, the IVT location and magnitude is shown in Figs. 6 and 7, where the left panels in Fig. 6 show the IVT during the time with largest precipitation accumulation. The map shows the orientation of the IVT and displays where the strongest vapor transport is positioned and, thus, which coastal area is targeted. The right panels of the figure give more detail of the AR's position and its evolution in time. In Fig. 7 cross sections upstream and close to each of the two catchments are used to show the IVT magnitude and its progression in time near the catchments. Looking at the three ensemble members in Fig. 6, the AR is located farther north in member 9 and it hits the Jølstra catchment more directly. The ARs in members 4 and 6 are located south of this catchment, which corresponds to member 9 producing the most precipitation here. For catchments average values, member 9 produces the most in Jølstra with $175 \mathrm{~mm}$, while members 4 and 6 have around 90 and $145 \mathrm{~mm}$ (Fig. 3). For Opo, member 9 produces the least (around $115 \mathrm{~mm}$ ) and member 6 produces the highest values $(220 \mathrm{~mm})$.

In the right panels in Fig. 6 the temporal evolution with latitude is given, which shows that the IVT in member 9 indeed is stronger just north of $60^{\circ} \mathrm{N}$, while members 4 and 6 are located just south of $60^{\circ} \mathrm{N}$. This is confirmed by looking at the IVT magnitude just upstream of the Jølstra catchment (Fig. 7), where member 9 has a higher magnitude than the other members, and the duration with such high values extends longer than in the others members. For Opo, the difference in the location of the AR is not as pronounced. IVT magnitude just upstream of the catchment shows that the member producing the highest accumulated precipitation is similar to the IVT values in the member producing least precipitation. This suggest that there are additional factors that cause differences in precipitation amounts. The catchment is smaller, and it

TABLE 1. PMP values for Jølstra and Opo calculated by MET Norway's standard statistical method.

\begin{tabular}{lccc}
\hline \hline \multicolumn{1}{c}{ Catchment } & $24 \mathrm{~h}$ & $48 \mathrm{~h}$ & $72 \mathrm{~h}$ \\
\hline Jølstra PMP (mm) & 360 & 470 & 560 \\
Opo PMP (mm) & 355 & 465 & 550 \\
\hline
\end{tabular}



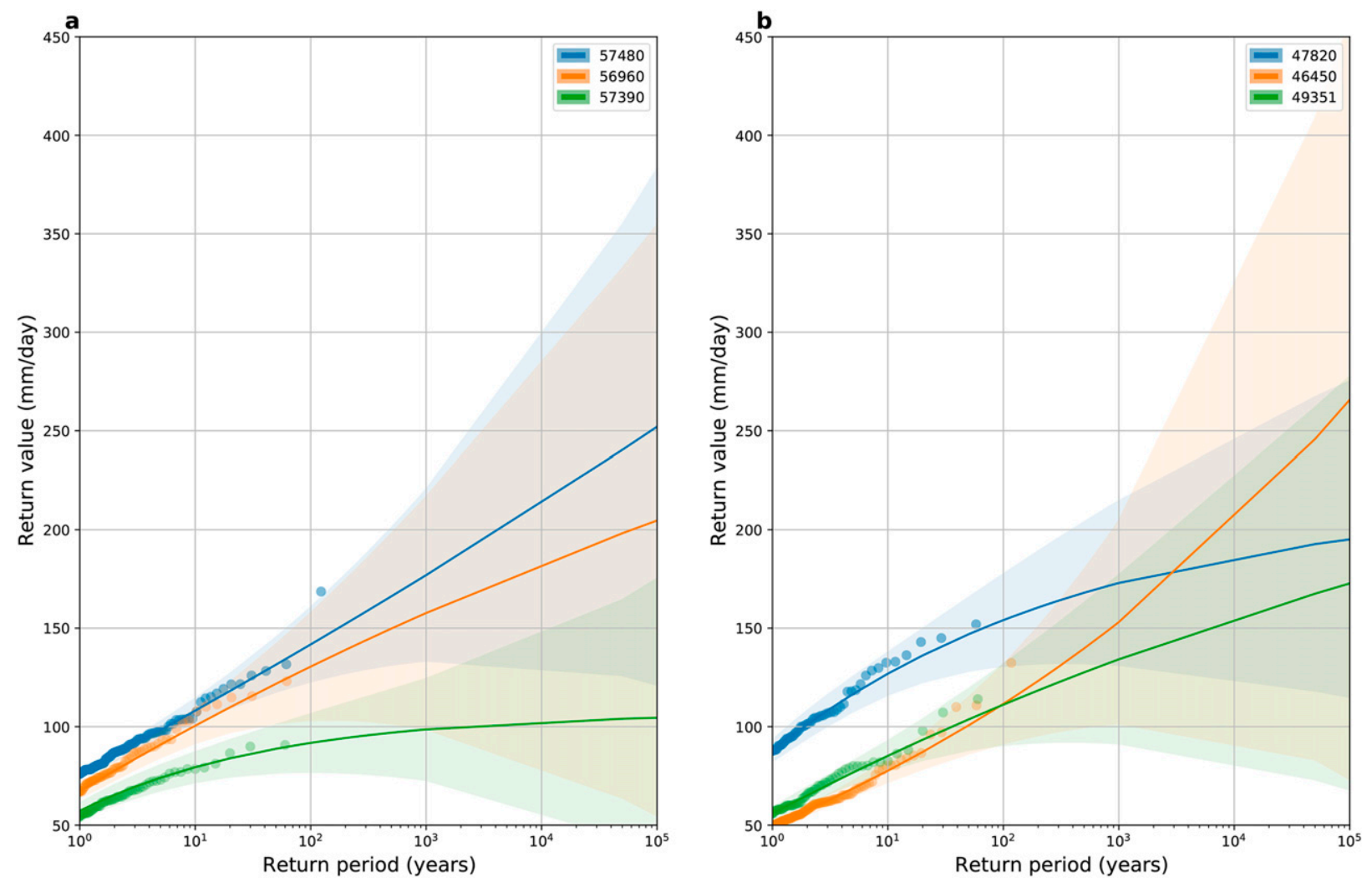

FIG. 5. Generalized extreme value distribution for three observation stations in (a) the area near the Jølstra catchment and (b) near the Opo catchment.

might be more sensitive to local orographic effects. When looking closer at the surface wind patterns during the time where the accumulation is greatest, the wind in member 6 turns to a more (steep) southwesterly direction than member 9 does (not shown). This can explain the precipitation amount in the member, which has a more preferable wind direction for producing precipitation. The catchment is situated downstream of a southwest-northeast-oriented fjord (Åkrafjorden).

Among all the members in the ensemble the distance between the ARs are not more than $270 \mathrm{~km}$. The AR located farthest south is at the southern tip of Norway, and the AR located farthest north is near the point farthest west in Norway. For Jølstra this results in a change in accumulated precipitation of about $75 \%$ for the member that has the AR more directly toward the catchment's location compared to the member with the AR not as favorable located. Thus, with this approach it is possible to shift the boundary conditions and, in turn, impact the areas which receive most precipitation. In general, the IVT of the ensemble members shows shifts of the AR location, as well as (in some members) the direction of the moisture flow, which has an impact of the resulting precipitation.

To better understand the limitations of our approach, due to the choice of one particular extreme event, we compare the IVT of the AROME-MetCoOp ensemble members with historical (1981-2018) extreme events (above the 99.5\% threshold) which occurred in the two catchments (Figs. 8 and 9 ). The composite map in Fig. 8 reveals that the moisture transport is located farther north in the events occurring in the catchment here (Fig. 8a), while there are higher IVT values in the events occurring in the catchment farthest south (Fig. 8b). Although the spatial spread of the IVT in the AROME-MetCoOp ensemble is as large as several hundred kilometers, it is still somewhat smaller than the one of the historical extreme events. The magnitude of extreme IVT, however, is consistent with the historical one (Fig. 9).

\section{Discussion and outlook}

One of the advantages of using numerical models for estimating PMP is the capability of producing data in areas where the observation network is limited. This ensures a complete spatial coverage, and the level of detail is determined by the spatial resolution of the model. The model simulations have to be sufficiently long, in order to get time series for a robust detection of events with return periods on the order of hundreds of years, which makes the computational cost high. To estimate PMP, which at least should exceed a return period on the order of 10000-40000 years (O. E. Tveito, MET Norway, 2020, personal communication), the magnitude of computational cost will make the task unrealistic in practice. A way to work around this is to select only the most extreme precipitation events and simulate these, as done in literature as well as in this study. The main approaches to maximize precipitation with numerical models are either to increase relative humidity, shift the boundary conditions in space, or a combination of the two. When 

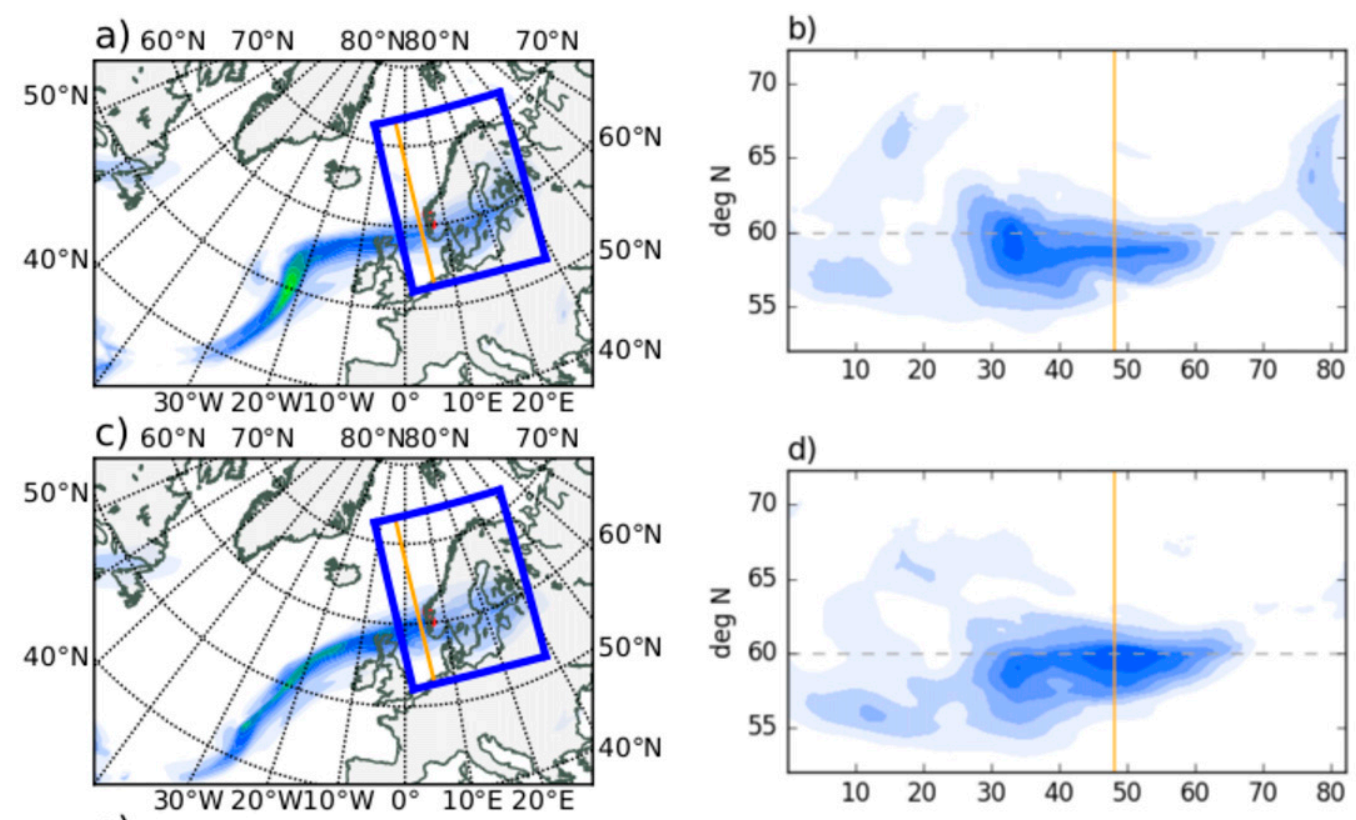

e) $60^{\circ} \mathrm{N} \quad 70^{\circ} \mathrm{N} \quad 80^{\circ} \mathrm{N} 80^{\circ} \mathrm{N} \quad 70^{\circ} \mathrm{N}$
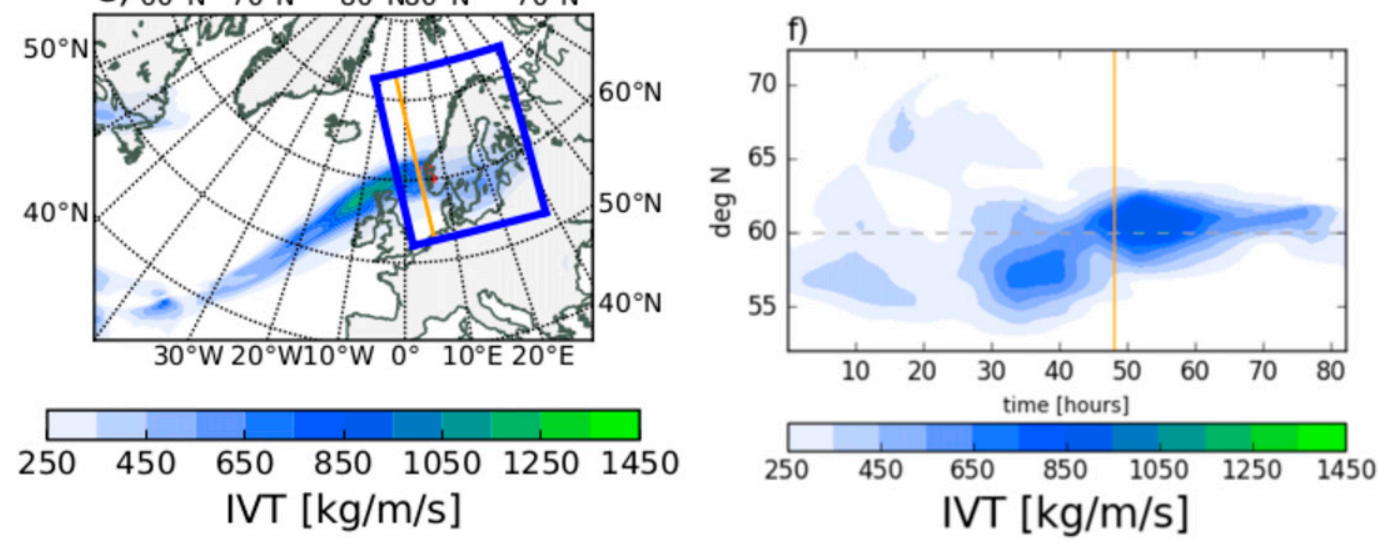

FIG. 6. Snapshot of IVT in EC-Earth ensemble (a) member 4, (c) member 6, and (e) member 9. The AROMEMetCoOp domain is shown by the blue box in the figures on the left, and the orange line shows the cross section for the Hovmöller diagrams on the right. The Hovmöller diagrams show IVT in EC-Earth ensemble (b) member 4, (d) member 6, and (f) member 9. The orange line in the Hovmöller diagrams indicate the time of the snapshot of IVT in the left panels, and the dashed gray line indicates the $60^{\circ} \mathrm{N}$ latitude.

shifting boundary conditions the goal is to make a historical rainstorm hit over a targeted area. To estimate the highest possible precipitation values over a catchment, the location of vapor flux is decisive. The approach presented here is to utilize a global climate model, which produces a 30 -yr present-day climate simulation and to select the most extreme precipitation event. This event is perturbed and 10 different ensemble members of the extreme event are downscaled with a regional weather prediction model. Thus, we have 10 different alterations of the lateral initial and boundary conditions for the regional model runs, which in turn provides 10 different realizations of an extreme precipitation event. Alteration of the initial and boundary conditions are done in a physically and dynamically consistent way.

In the present study we performed a detailed analysis on the effect of the large-scale modification of the IVT on the precipitation on catchment scale. Two catchments are selected, which are frequently impacted by AR induced extreme precipitation events and are embedded in the complex topography of western Norway. For one of the catchments we find that the AR is shifted by about $270 \mathrm{~km}$, which has a downstream impact on the amount of precipitation by about $75 \%$. For the other catchment, the main reason for a change of precipitation is not the translation of the AR, but the change in direction of the main vapor transport.

The two catchments are situated in complex terrain and, while this region in Norway is the wettest part of the country, local differences exist. This is illustrated by Fig. 5 where the generalized extreme value distributions for two of the stations in each catchment area are shown. In particular, one of the stations in Opo (Fig. 5b) shows a strikingly different distribution than the other 
a)

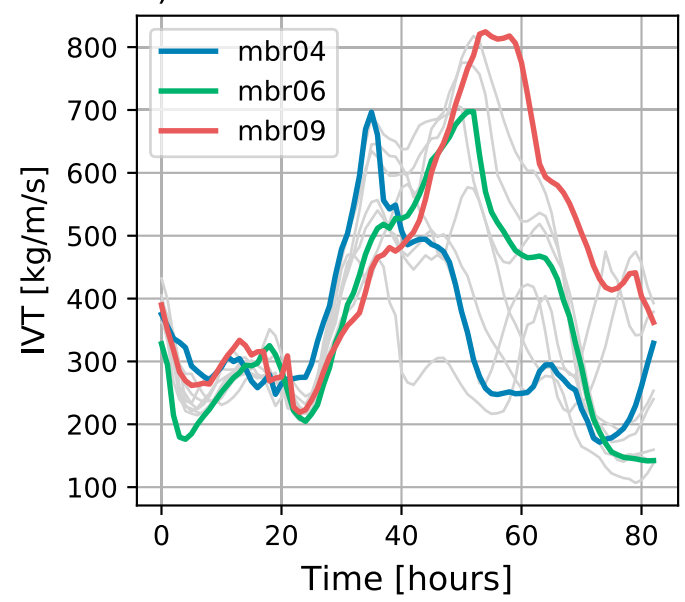

b)

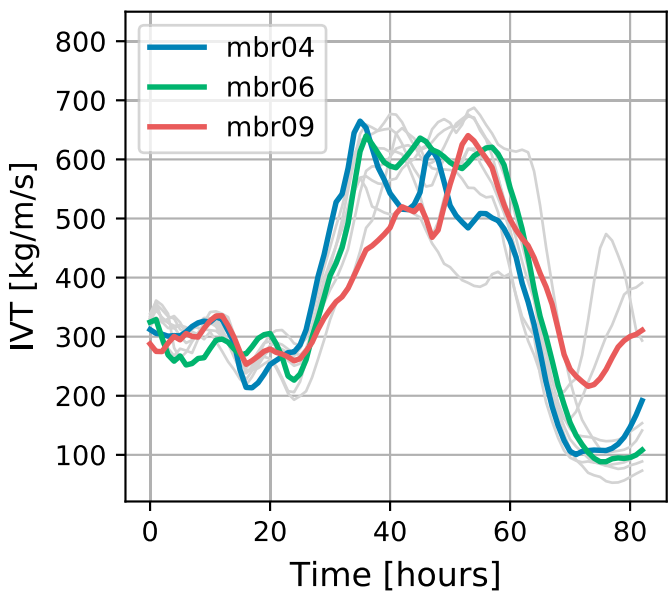

FIG. 7. IVT in AROME-MetCoOp upstream of the two catchments, (a) Jølstra and (b) Opo. The evolution of IVT in time is shown along a 7.5-km-long cross section located west of the corresponding catchment.

two, even though they are located only $25 \mathrm{~km}$ apart. Compared with statistically derived PMP estimates the model results are lower, but return periods on the order of $10^{4}$ years are reached.

The comparison with ERA5 reanalysis data shows that the models are capturing the IVT extremes and that the different ensemble members cover partly the range of IVT extremes observed in the past 40 years. This is especially true for the northernmost catchment, where the AROME-MetCoOp well matches IVT values from the past events farther away from the west coast of Norway. For the other catchment, the ARs in the ensemble are not targeting the catchment as successful. The event detection in the very first step of the model chain selected events from daily precipitation covering all of the west coast. In further studies this step should be refined and the event detection could be done on a more local scale.

Here, we have demonstrated the use of a method that is not bounded to the relatively short history of observed events, but utilizes a model chain to create physically consistent synthetic events and is giving reasonable results. However, estimating PMP values takes more than the highest value out of 10 ensemble members, and the approach presented here is to be regarded as a step toward a comprehensive method. The suggested approach will modify the boundary and initial conditions in a physical and dynamical way ensuring the physics to remain realistic.

We conclude that the described approach can be used as a method to alter the initial and boundary conditions in order to derive PMP values for a given catchment. To ensure that the model setup for estimating PMP is done in the most physically realistic manner, there is a need to investigate how alterations of one rainfall event changes the precipitation pattern over selected catchments. We can show that small changes in position and orientation of the moisture flow, induced by the ensemble approach, lead to relative large changes in precipitation values.

Our study has a specific focus on the large-scale precipitation events caused by ARs and orographic precipitation, a) $60^{\circ} \mathrm{N} \quad 70^{\circ} \mathrm{N} \quad 80^{\circ} \mathrm{N} 80^{\circ} \mathrm{N} \quad 70^{\circ} \mathrm{N}$

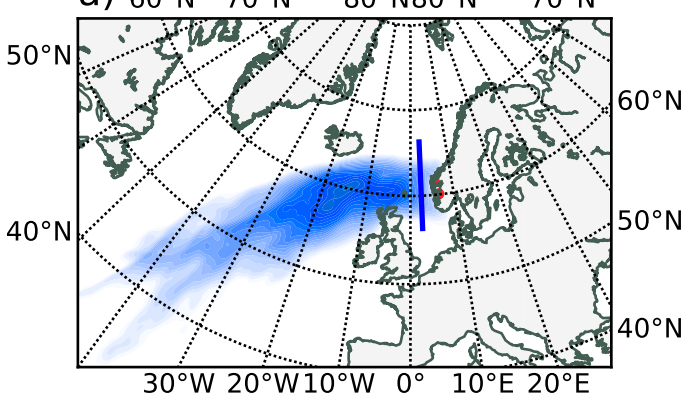

b) $60^{\circ} \mathrm{N} \quad 70^{\circ} \mathrm{N} \quad 80^{\circ} \mathrm{N} 80^{\circ} \mathrm{N} \quad 70^{\circ} \mathrm{N}$

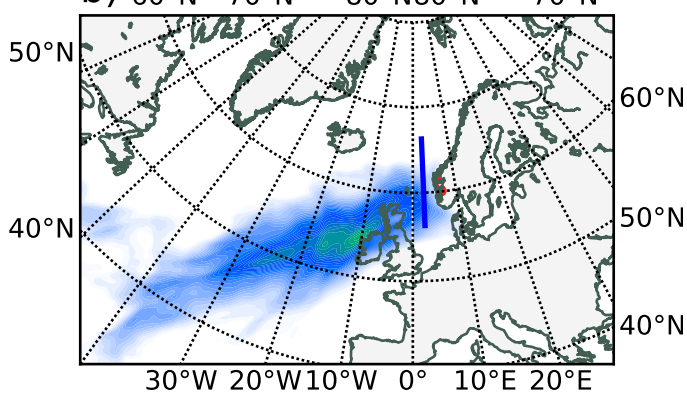

$50^{\circ} \mathrm{N}$

\section{$40^{\circ} \mathrm{N}$}

\section{0 \\ IVT $[\mathrm{kg} / \mathrm{m} / \mathrm{s}]$}

FIG. 8. Map of IVT composite from the events with precipitation above the $99.5 \%$ threshold from the stations in the (a) Jølstra area and (b) Opo area. Data are taken from the ERA5 reanalysis dataset. The blue line indicates the cross section used in Fig. 9. 

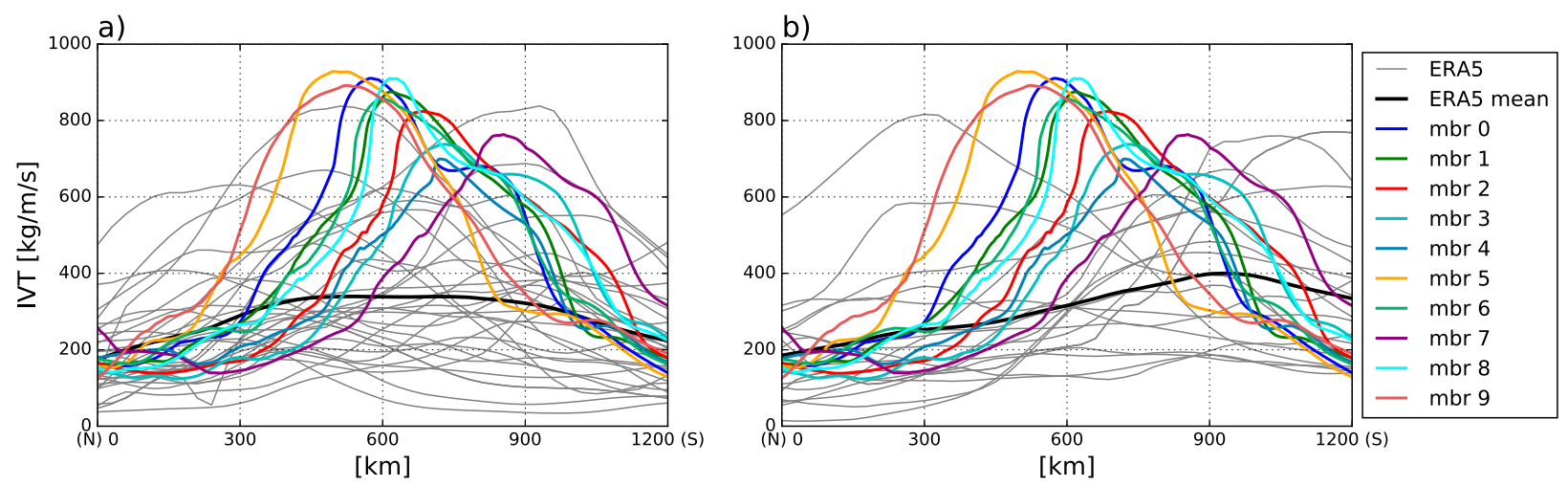

FIG. 9. IVT in ERA5 along the cross section given by the blue line in Fig. 8, for the same events (gray thin lines). The thick gray line shows the mean IVT in the events. The colored lines show the IVT values in the AROME-MetCoOp ensemble.

which is the major mechanism for extreme precipitation at the Norwegian west coast. Convective events producing heavy precipitation are neglected although, farther inland convective events can cause extreme precipitation amounts that result in damages to infrastructure with severe consequences for society. This has not been the focus in this study, nevertheless, the model in use is a convection permitting model, and has the ability to be applied in a convective historical storm.

PMP estimates are, together with snowmelt, input parameters for watershed models when estimating probable maximum flood (PMF). In this framework, the determination of precipitation phase is important. The aim of the study presented in this paper is to investigate if the ensemble approach can be an alternative to the physically more inconsistent artificial manipulations of initial and boundary conditions in the NWP model, and not in the detail of precipitation phase, though that would be needed in the determination of PMF.

In general, in order to utilize an ensemble approach for the estimation of PMP more of the most extreme precipitation events would have to be resimulated. To meet these challenges with realistic computational costs, a possible approach could be to utilize already established ensembles from numerical seasonal or weather forecasting systems. Multiyear hindcast datasets of seasonal prediction systems are available; their different ensemble members can provide for a valuable extreme event dataset. From this dataset there is a possibility to find the most extreme precipitation events and to downscale to catchments of interest. This is a proposed outlook that should be explored, and if it is found feasible, it has the potential to cover catchments for larger areas than in this case study.
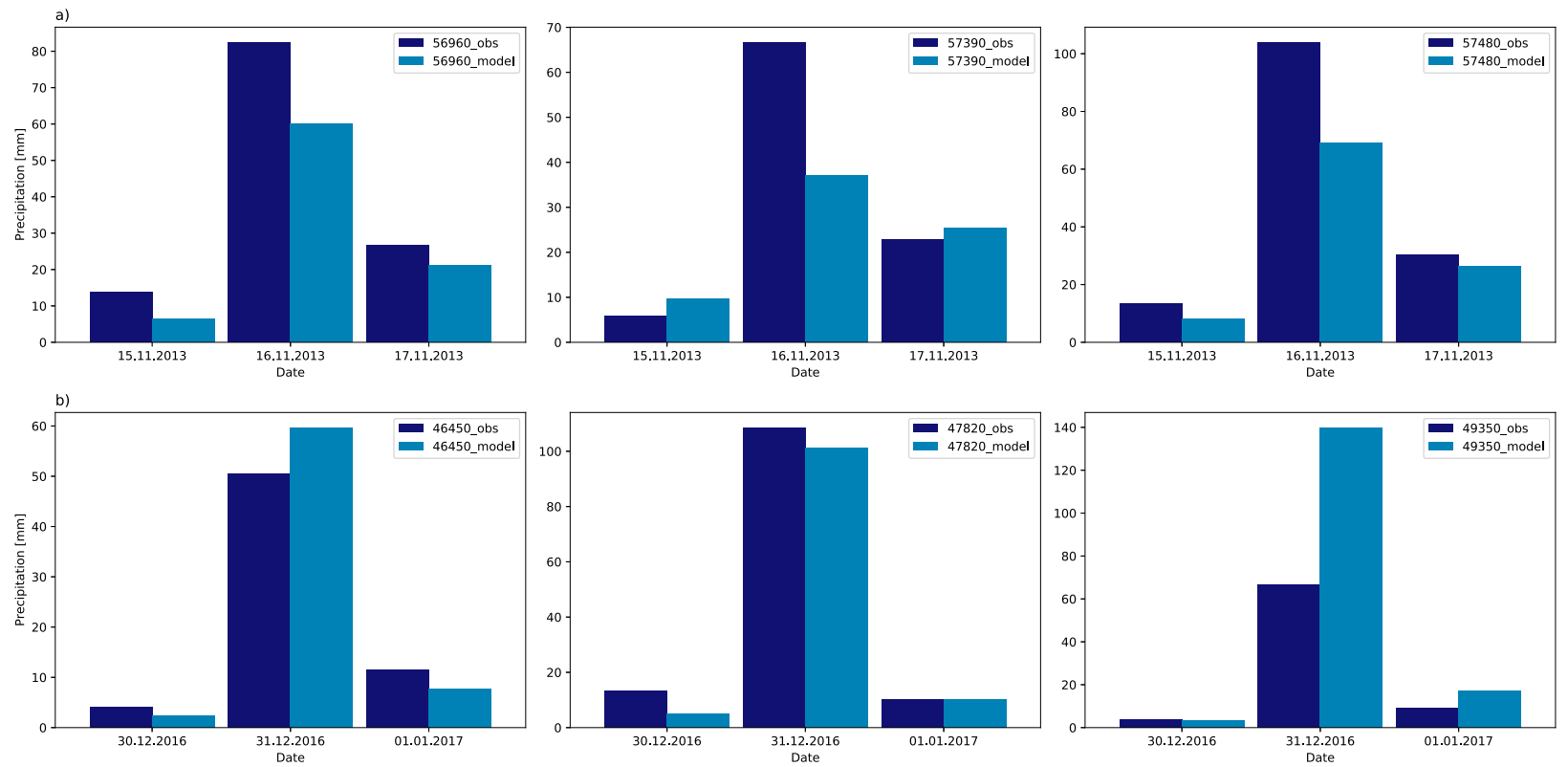

FIG. A1. Comparison of precipitation values from AROME-MetCoOp and observations from three stations near (a) the Jølstra catchment and (b) the Opo catchment from two extreme precipitation events. Daily accumulated values are shown over three days. The observations are done from 0600 to 0600 UTC, and the model values are calculated over the same time period. 
Acknowledgments. The study is supported by the Norwegian Research Council and Energi Norge through the project FlomQ (NFR-235710/E20). MM has received support from the project TWEX (NFR-255037) funded through the Norwegian Research Council. We acknowledge the TWEX project team for providing the model simulations, and we are thankful for discussions with this group, especially Jana Sillmann and Nathalie Schaller. We are also thankful for helpful discussions with Thordis L. Thorarinsdottir and Morten A. Ø. Køltzow.

\section{APPENDIX}

\section{Comparison of AROME-MetCoOp and Observations}

A comparison of precipitation values from AROMEMetCoOp and observations from three stations near the Jølstra and Opo catchment from two extreme precipitation events is shown in Fig. A1.

\section{REFERENCES}

Azad, R., and A. Sorteberg, 2017: Extreme daily precipitation in coastal western Norway and the link to atmospheric rivers. J. Geophys. Res. Atmos., 122, 2080-2095, https://doi.org/ 10.1002/2016JD025615.

Ben Alaya, M. A., F. Zwiers, and X. Zhang, 2018: Probable maximum precipitation: Its estimation and uncertainty quantification using bivariate extreme value analysis. J. Hydrometeor., 19, 679-694, https://doi.org/10.1175/JHM-D-17-0110.1.

Benedict, I., K. Ødemark, T. Nipen, and R. Moore, 2019: Largescale flow patterns associated with extreme precipitation and atmospheric rivers over Norway. Mon. Wea. Rev., 147, 14151428, https://doi.org/10.1175/MWR-D-18-0362.1.

Chen, X., and F. Hossain, 2018: Understanding model-based probable maximum precipitation estimation as a function of location and season from atmospheric reanalysis. J. Hydrometeor., 19, 459-475, https://doi.org/10.1175/JHM-D-17-0170.1.

Dee, D. P., and Coauthors, 2011: The ERA-Interim reanalysis: Configuration and performance of the data assimilation system. Quart. J. Roy. Meteor. Soc., 137, 553-597, https://doi.org/ 10.1002/qj.828.

Førland, E. J., 1992: Manual for beregning av påregnelige ekstreme nedbørverdier (in Norwegian). DNMI Rep. 21/92, 44pp.

Gilleland, E., and R. Katz, 2016: Extremes 2.0: An extreme value analysis package in R. J. Stat. Software, 72, 1-39, https:// doi.org/10.18637/jss.v072.i08.

Haarsma, R. J., W. Hazeleger, C. Severijns, H. de Vries, A. Sterl, R. Bintanja, G. J. van Oldenborgh, and H. W. van den Brink, 2013: More hurricanes to hit western Europe due to global warming. Geophys. Res. Lett., 40, 1783-1788, https://doi.org/10.1002/grl.50360.

Hazeleger, W., and Coauthors, 2010: EC-Earth: A seamless Earthsystem prediction approach in action. Bull. Amer. Meteor. Soc., 91, 1357-1364, https://doi.org/10.1175/2010BAMS2877.1.

Hegdahl, T. J., K. Engeland, M. Müller, and J. Sillmann, 2020: An eventbased approach to explore selected present and future atmospheric river-induced floods in western Norway. J. Hydrometeor., 21, 20032021, https://doi.org/10.1175/JHM-D-19-0071.1.

Hersbach, H., and Coauthors, 2018: Operational global reanalysis: Progress, future directions and synergies with NWP. ERA Rep. Series 27, 63 pp., https://www.ecmwf.int/sites/default/ files/elibrary/2018/18765-operational-global-reanalysis-progress-future-directions-and-synergies-nwp.pdf.
Ishida, K., M. L. Kavvas, S. Jang, Z. Q. Chen, N. Ohara, and M. L. Anderson, 2015a: Physically based estimation of maximum precipitation over three watersheds in Northern California: Atmospheric boundary condition shifting. J. Hydrol. Eng., 20, 04014052, https://doi.org/10.1061/(ASCE) HE.1943-5584.0001026.

,,,,---- , and,$- 2015 \mathrm{~b}$ : Physically based estimation of maximum precipitation over three watersheds in Northern California: Relative humidity maximization method. J. Hydrol. Eng., 20, 04015014, httsp://doi.org/10.1061/(ASCE) HE.1943-5584.0001175.

Klemeš, V., 1993: Probability of extreme hydrometeorological events - a different approach. IAHS Publ., 213, 167-176.

Lussana, C., T. Saloranta, T. Skaugen, J. Magnusson, O. E. Tveito, and J. Andersen, 2018: seNorge 2 daily precipitation, an observational gridded dataset over Norway from 1957 to the present day. Earth Syst. Sci. Data, 10, 235-249, https://doi.org/ 10.5194/essd-10-235-2018.

Micovic, Z., M. G. Schaefer, and G. H. Taylor, 2015: Uncertainty analysis for probable maximum precipitation estimates. J. Hydrol., 521, 360-373, http://doi.org/10.1016/j.jhydrol.2014.12.033.

Müller, M., and Coauthors, 2017: AROME-MetCoOp: A Nordic convective-scale operational weather prediction model. Wea. Forecasting, 32, 609-627, https://doi.org/10.1175/WAF-D-160099.1.

NERC, 1975: Meteorological Studies. Vol. II, Flood Studies Report, National Environmental Research Council, 91 pp.

Ohara, N., M. L. Kavvas, S. Kure, Z. Q. Chen, S. Jang, and E. Tan, 2011: Physically based estimation of maximum precipitation over American River Watershed, California. J. Hydrol. Eng., 16, 351-361, https://doi.org/10.1061/(ASCE)HE.1943-5584.0000324.

Owens, R. G., and T. Hewson, 2018: ECMWF forecast user guide. ECMWF, https://doi.org/10.21957/m1cs7h.

Papalexiou, S. M., and D. Koutsoyiannis, 2006: A probabilistic to the concept of Probable Maximum Precipitation. Adv. Geosci., 7, 51-54, https://doi.org/10.5194/adgeo-7-51-2006.

Rouhani, H., and R. Leconte, 2016: A novel method to estimate the maximization ratio of the Probable Maximum Precipitation (PMP) using regional climate model output. Water Resour. Res., 52, 7347-7365, https://doi.org/10.1002/2016WR018603.

Rutz, J. J., W. J. Steenburgh, and F. M. Ralph, 2014: Climatological characteristics of atmospheric rivers and their inland penetration over the western United States. Mon. Wea. Rev., 142, 905-921, https://doi.org/10.1175/MWR-D-13-00168.1.

Schaller, N., and Coauthors, 2020: The role of spatial and temporal model resolution in a flood event storyline approach in western Norway. Wea. Climate Extremes., 29, 100259, https:// doi.org/10.1016/j.wace.2020.100259.

Seity, Y., 2011: The AROME-France convective-scale operational model. Mon. Wea. Rev., 139, 976-991, https://doi.org/10.1175/ 2010MWR3425.1.

Toride, K., 2019: Model-based probable maximum precipitation estimation: How to estimate the worst-case scenario induced by atmospheric rivers? J. Hydrometeor., 20, 2383-2400, https:// doi.org/10.1175/JHM-D-19-0039.1.

Whan, K., J. Sillmann, N. Schaller, and R. Haarsma, 2020: Future changes in atmospheric rivers and extreme precipitation in Norway. Climate Dyn., 54, 2071-2084, https://doi.org/10.1007/ s00382-019-05099-z.

WMO, 2009: Manual on estimation of probable maximum precipitation (PMP). Tech. Rep. WMO-1045, 257 pp., http:// www.wmo.int/pages/prog/hwrp/publications/PMP/WMO \% $201045 \% 20$ en.pdf. 